\title{
Peri-Implant Soft Tissue Esthetics; A Journey from Implant Placement to Permanent Restoration
}

\author{
Fahad Umer ${ }^{1}$ \\ Samira Adnan ${ }^{2}$ \\ Muhammad Rizwan Nazeer ${ }^{3}$ \\ BDS, FCPS, FICOI, CAGS U-PENN \\ BDS, FCPS \\ BDS
}

\begin{abstract}
:
Restorations placed in the anterior part of the mouth present a unique challenge in terms of reproducing the lost soft tissue. This aspect is particularly pronounced in case of avulsed central incisors. Since 'black triangles' have been displayed in patients where the anterior teeth are replaced by implants, particular attention needs to be paid to achieve the desired soft tissue profile. This case-report explains the restoration of upper central and lateral incisors of a patient, where the central incisor was avulsed and lateral incisor fractured. The process of replacing the central incisor with an immediate implant, followed by slowly and gradually modifying the peri-implant soft tissue, leading up to transferring the modified soft tissue profile through a specialized impression technique, has been described in detail.
\end{abstract}

KEYWORDS: Facial aesthetics, black triangle, upper central incisor, screw retained implant, cement retained implant special impression technique.

HOW TO CITE: Umer F Adnan S, Nazeer MR. Peri-Implant Soft Tissue Esthetics; A Journey from Implant Placement to Permanent Restoration. J Pak Dent Assoc 2017; 26(2): 83-89.

Received: 8 December 2016, Accepted: 15 March 2017

\section{INTRODUCTION}

$\mathrm{R}$ estoring aesthetics in the anterior part of the mouth after trauma is a challenging endeavor. There are multitude of reasons ascribed to failure of restorations in the anterior region of the mouth, but most are essentially esthetic concerns ${ }^{1}$. One of the ideal methods to replace a lost permanent incisor is the placement of an implant. But replacing the missing tooth with an implant does not automatically achieve ideal aesthetics for the anterior teeth ${ }^{2}$. The infamous 'black triangle' has widely been reported in patients rehabilitated with dental implants ${ }^{3}$. According to the patient's soft tissue profile, the soft tissue surrounding the implant has to be modified over a period of time in order to achieve the desired soft tissue architecture ${ }^{4}$. This calls for an interim restoration of such dimensions and quality that sculpts and supports the soft tissue, while

1. Assistant Professor and Consultant, Operative Dentistry, The Aga Khan University and Hospital, Karachi, Pakistan

2. Assistant Professor, Operative Dentistry, Sindh Institute of Oral Health Sciences, Jinnah Sindh Medical University, Karachi, Pakistan

3. FCPS-II Resident Operative Dentistry, The Aga Khan University Hospital, Karachi, Pakistan

Corresponding author: "Dr. Samira Adnan"

<nnmst@hotmail.com> maintaining acceptable aesthetics and without causing any trauma to the soft tissue ${ }^{5}$. This case-report explains the restoration of upper central and lateral incisors of a patient, where the central incisor was avulsed and lateral incisor fractured. The process of replacing the missing central incisor with an immediate implant, followed by the gradual modification of the peri-implant soft tissue, and then transferring the modified soft tissue profile through a specialized impression technique, has been described in this case report.

\section{CASE REPORT}

A 42 year old female patient came to our Dental Clinic, having suffered from dental trauma one day before (Fig. 1). On clinical examination, it was seen that the patient had an avulsed upper left central incisor and coronal fracture (Ellis class III) of upper left lateral incisor with visible pulp exposure (Fig. 2). A periapical radiograph of the upper left anterior segment showed complete absence of upper left central incisor (Fig. 3). As the retrieved tooth was kept dry and its re-implantation wound have ultimately lead to ankylosis and related complications, it was planned to place an immediate implant for replacement of 21 along with root canal treatment on the 22. After explaining the treatment 
plan to the patient and obtaining their consent, the patient's treatment was commenced.

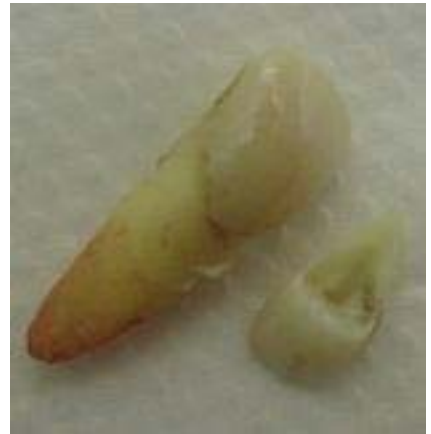

Fig. (1). Avulsed upper left central and fractured portion of left lateral incisor.

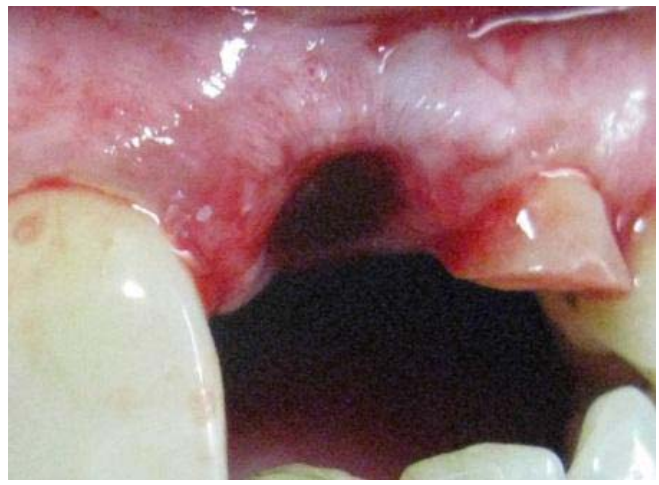

Fig. (2). A clinical picture showing an avulsed central incisor and an ellis type III fracture of left lateral incisor.

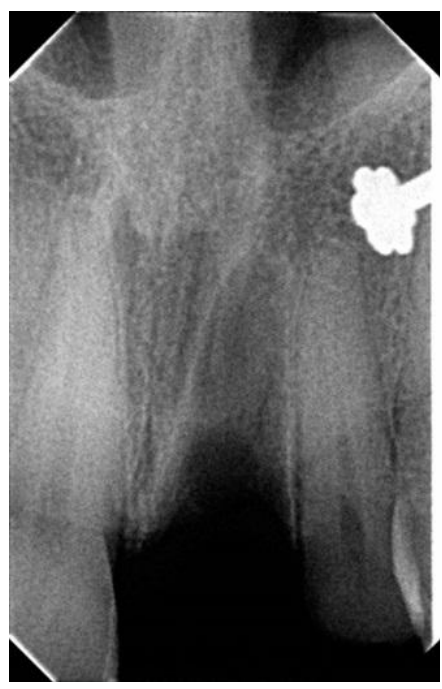

Fig. (3). Initial periapical radiograph showing an empty socket and fractured lateral incisor.
Local anesthesia (1.7 $\mathrm{ml}$ of $2 \%$ Xylestine 1:80,000) was administered and osteotomy was started. The final drill was $3.2 \mathrm{~mm}$ width with a length of $12.5 \mathrm{~mm}$. Afterwards, a $3.8 \mathrm{~mm}$ width and $10.5 \mathrm{~mm}$ length implant was placed in the osteotomy site (Fig. 4). The primary stability was of $30 \mathrm{Ncm}$ was achieved. The implant had $3.5 \mathrm{~mm}$ platform (Biohorizons tapered internal hex laser lok). Healing abutment (Bio-horizons $3.5 \mathrm{~mm}$ width) was placed at the same appointment (Fig. 5). Meanwhile, root canal treatment was completed on 22. The tooth was prepared as to receive a PFM crown. Since the torque on the implant replacing the central incisor was less than $45 \mathrm{~N} / \mathrm{cm} 2$, screw retained temporary crown could not be fabricated at that time. A temporary crown was made for 22, to which a crown for the missing 21 was cantilevered. The temporary restoration was cemented with temporary cement.

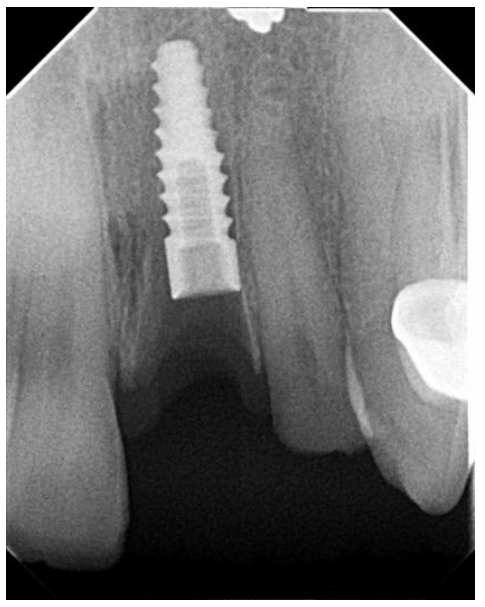

Fig. (4). Periapical radiograph showing implant placement at avusled side (\#21).

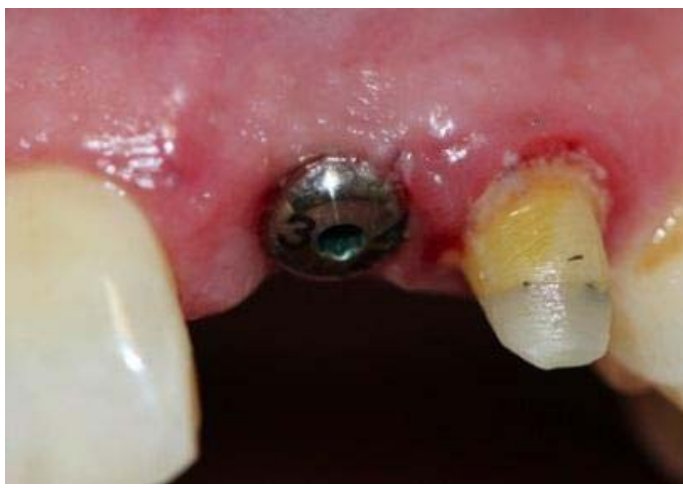

Fig. (5). Clinical picture after healing collar placement.

At follow-up visit after two weeks, the patient was assessed for any uneventful healing. 
At the next appointment which was after three months, a peri-apical radiograph revealed an integrated implant with absence of any pathology. After exposure, the implant exhibited secondary stability and hence, a healing abutment with regular emergence $5 \mathrm{~mm}$ height (TP3HA5L) was placed. At the next appointment after three weeks, it was decided to place a lab fabricated screw retained temporary crown to improve soft tissue profile.

Consequently, an impression was done with a laser-lok Biohorizons titanium abutment (PYTTH) using addition silicon (Fig. 6). All parameters for an esthetic restoration, like smile line, lip line, lip position, and facial profile were recorded. At the subsequent appointment, the screw-retained temporary was placed and hand tightened (Fig. 7).

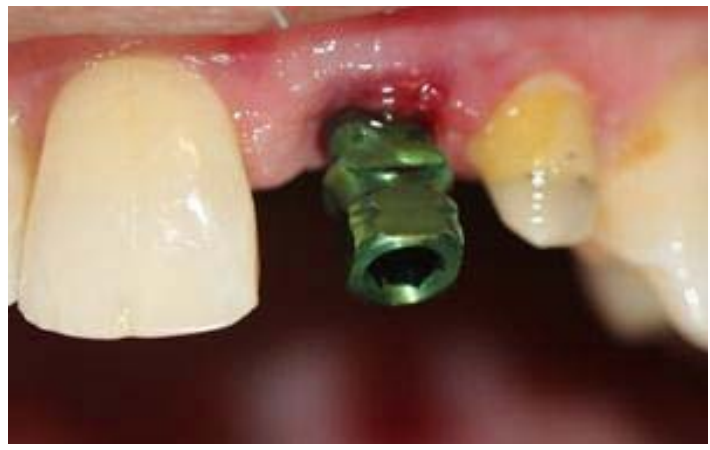

Fig. (6). Laser lok Biohorizons titanium abutment placement for final putty impression.

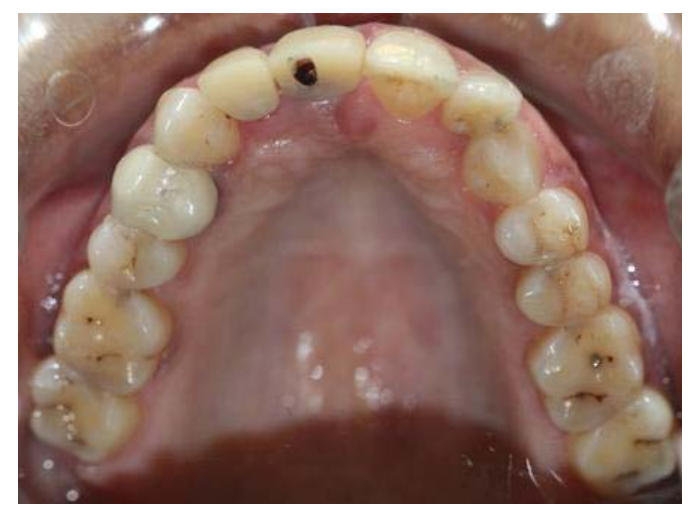

Fig. (7). The screw-retained temporary was placed and hand tightened.

After two weeks, composite restoration was added only at the gingival margins of the temporary restoration, gradually modifying the restoration and gently sculpting the soft tissue in that area. Consequently, after three months, both the clinician and patient were satisfied with the gingival esthetics (Fig. 8). Next, the impression was taken to transfer the peri-implant soft tissue profile to the permanent restoration. This involved the removing the temporary crown, (Fig. 9) then attaching an implant analogue to it (Fig. 10).

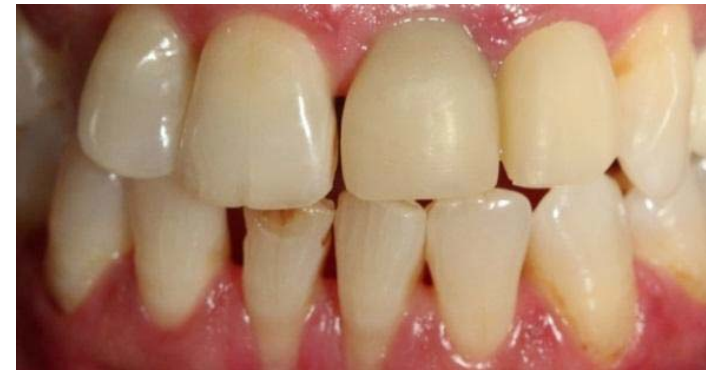

Fig. (8). Frontal view after 3 months follow up. Note the improvement in gingival aesthetics.

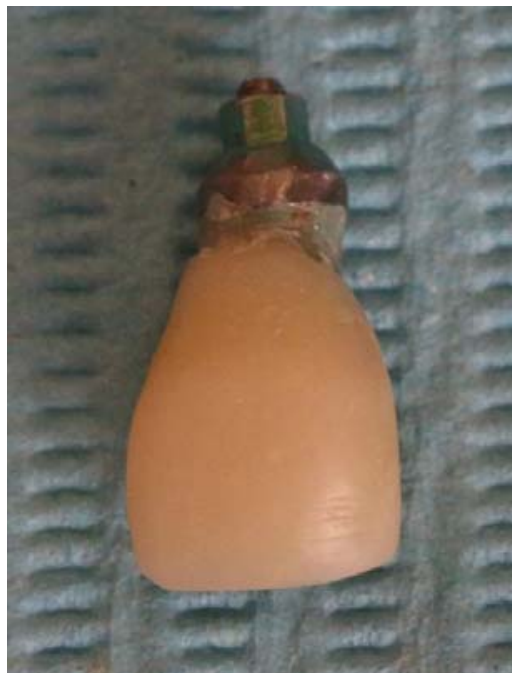

Fig. (9). Removal of abutment crown for sterlization.

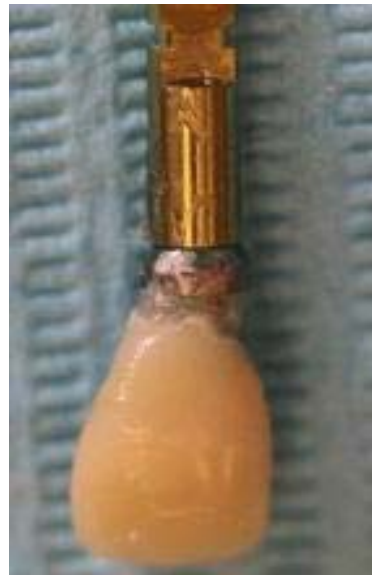

Fig. (10). Connecting implant analogue to temporary crown. 


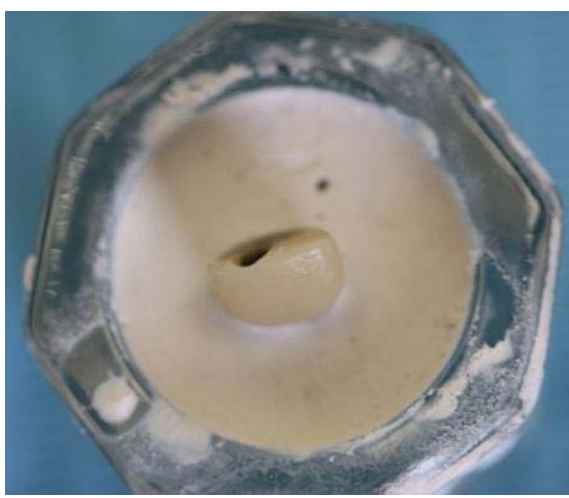

Fig. (11). Assembly for recording the free gingival margin.

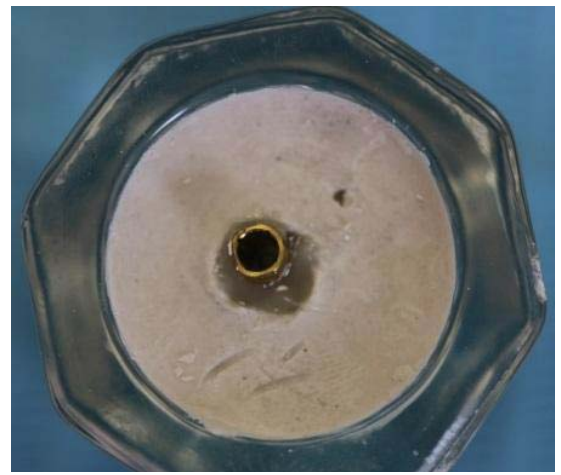

Fig. (12). The surrounding space around the abutment was filled using light cured flowable composite.

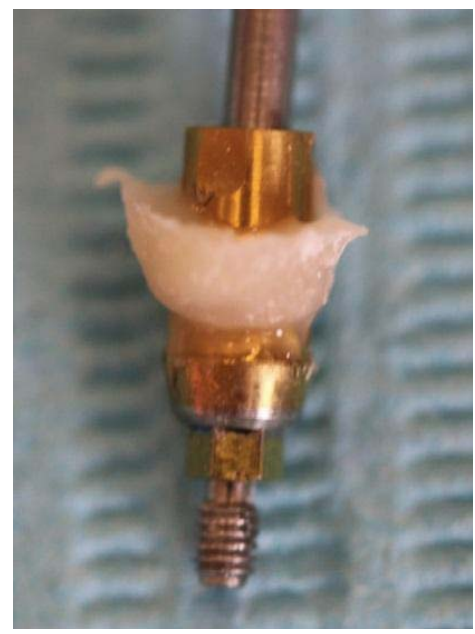

Fig. (13). Permanent abutment with the collar of composite mimicking the soft tissue profile around the implant was removed.

This assembly was then stabilized and plaster was poured around it, making sure that the gingival tissue, from the implant collar till the free gingival margin, was adequately recorded (Fig. 11). Once the plaster was set, the temporary

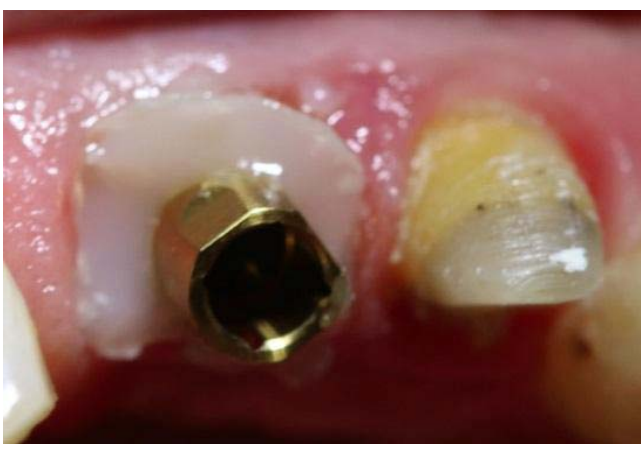

Fig. (14). The assembly was then placed inside the patient's mouth while confirming the facial and lingual orientation.

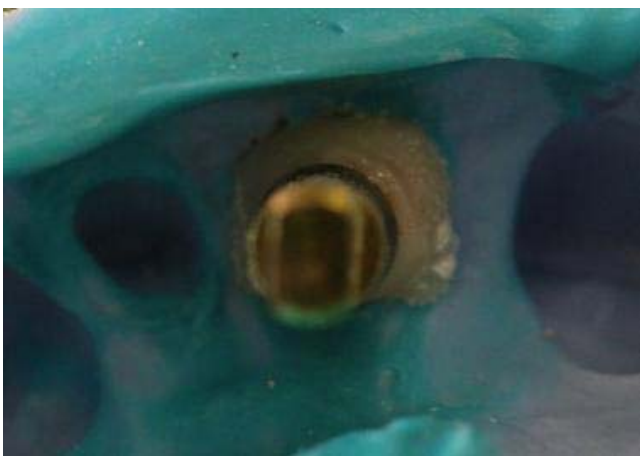

Fig. (15). The picking of modified permanent abutment in the impression.

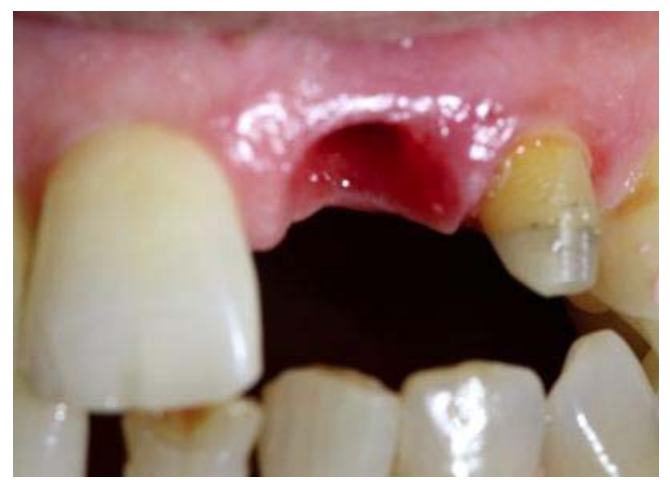

Fig. (16). Soft tissue aesthetics after removal of temporary crown.

crown was removed from the implant analogue and the permanent abutment was attached. The surrounding space around the abutment was filled using light cured flowable composite, (Fig. 12). The composite was cured and the permanent abutment with the collar of composite mimicking the soft tissue profile around the implant was removed (Fig. 13). This assembly was then placed inside the patient's mouth while confirming the facial and lingual orientation 


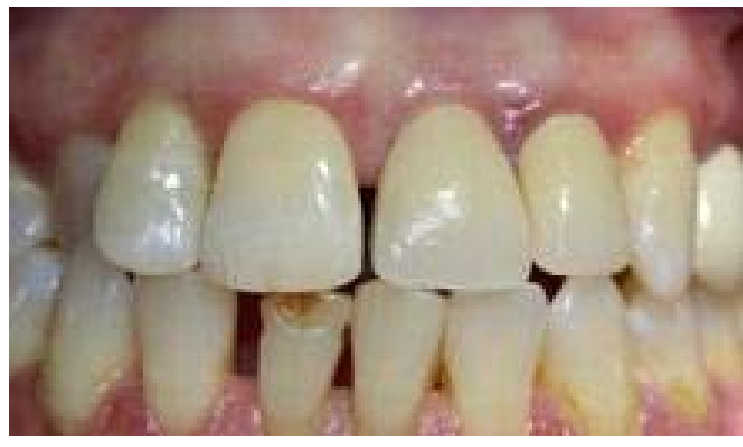

Fig. (17). Soft tissue appearance after final crown cementation.

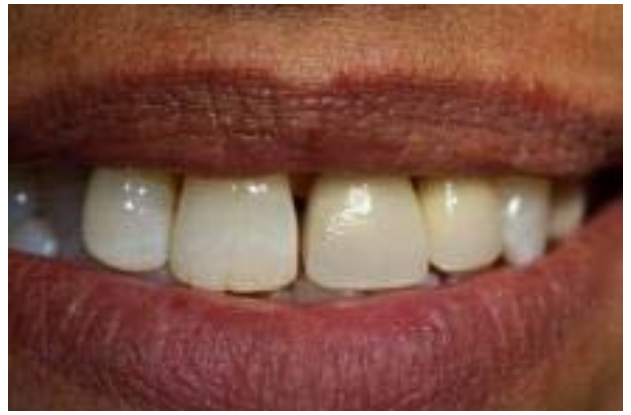

Fig. (18). Final crown in place.

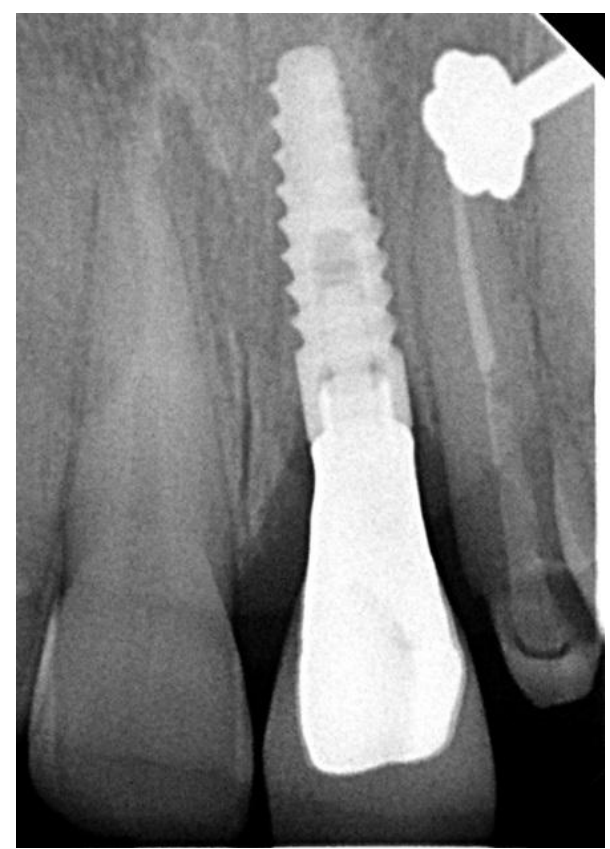

Fig. (19). Periapical radiograph after crown Cementation.

(Fig. 14). The impression was taken with modified permanent abutment picked up in the impression (Fig. 15), the implant analogue was attached to it and dental stone
(Plaster Neelkanth stone) poured. Once the plaster was set, the composite around the abutment was removed. The temporary crowns were replaced in the patient's mouth and patient recalled after one week. In the meantime, the permanent crowns were fabricated in the laboratory, with external contours following the soft tissue profile of the patient developed over time. In the next appointment, the temporary restorations were removed (Fig. 16), and the permanent crowns were cemented (Figs. 17, 18). The patient was satisfied with the appearance of the final restorations and a follow-up radiograph and cone beam CT scan (Carestream CS 93000 Gallileo) done six months after delivery of the crown showed adequate healing and no signs of peri-implant disease and an intact labial plate of bone (Figs. 19, 20).

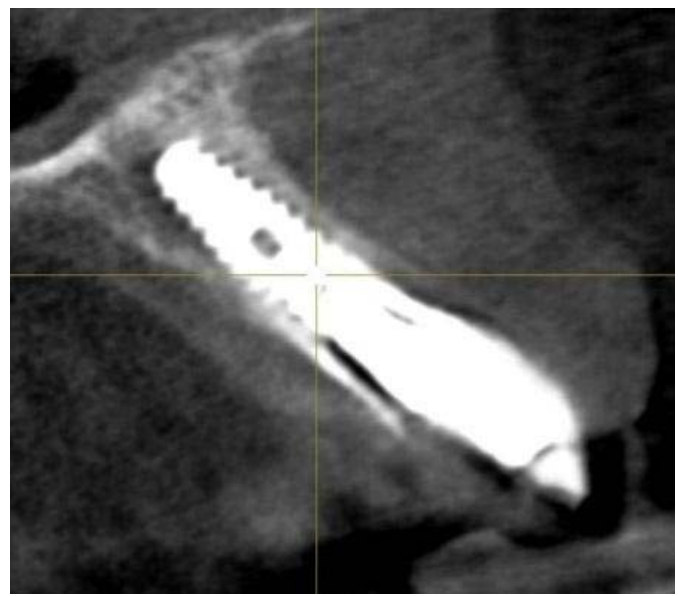

Fig. (20). Six months follow up CT scan showing intact labial plate of bone.

\section{DISCUSSION}

Re-establishing aesthetics after trauma in the anterior region of the mouth is a challenge, especially in cases of avulsion. A viable option for replacement of such a tooth is immediate implant placement. Our patient was a healthy individual with adequate amount of bone, which made her an ideal candidate for immediate implant placement ${ }^{6}$.

The goal was to preserve the gingival tissue architecture with the help of well-made temporary restoration, until the time the implant had osseointegrated ${ }^{7}$. Although primary stability was achieved but was less than $30 \mathrm{Ncm}$ and therefore a screw-retained temporary crown could not be placed. This resulted in loss of the pre-existing gingival architecture of the patient, which had to be re-established with the help of customized temporary crown. The disadvantage of using a wider implant in the anterior maxillary region is the potential to damage the thin labial 
plate of bone, which can result in compromised aesthetics. In this case, the osteotomy site for the implant was intentionally prepared palatally in order to preserve the labial plate of bone and prevent any esthetic dilemma ${ }^{8}$.

One of the complications of implant placement in the anterior region of the mouth is labial bone dehiscence or fenestration ${ }^{9}$. Careful and atraumatic implant placement is one way of ensuring the integrity of the buccal cortical plate. In our patient, the buccal bone was intact and of adequate thickness, and hence was demonstrated to be preserved in the follow-up radiographs and CT scan.

Placing an implant in the socket immediately after extraction helps preserve the dimensions of the alveolar socket as well as the profile of the soft tissue ${ }^{10}$.

Temporary restorations placed after implant insertion play an essential role in maintaining the esthetics until the implant osseo-integrates ${ }^{11}$. The temporary restoration that was provided to the patient initially did not provide optimum contouring of the soft tissue. Hence, the screw retained temporary restoration was contoured and altered over a period of three months, allowing the surrounding tissue to mould and mature and providing time for the implant to osseo-integrate. The temporary restorations were previously modified using self-cure acrylic but this practice has been discontinued due to concerns with uncured resin deep in soft tissue surrounding the implant causing trauma ${ }^{12}$. Instead, composite is used now as it can added incrementally, has better handling properties and is tissue-friendly.

The effort exercised in maintaining the architecture of the peri-implant gingival tissues is paid off only if it is successfully translated into the permanent restoration. The most basic method includes removing the temporary restoration and obtaining an implant level impression ${ }^{13}$. There can be some issues in this technique as depending on the depth of the implant placement, the impression material may not completely record the entire soft tissue profile of the peri-implant region. Other methods include the use of the temporary restoration, as was followed in our patient. Modifications for this particular technique are using putty instead of plaster to be applied around the temporary crown, 14 or using an impression coping instead of the permanent abutment while applying flowable composite to modify it for use in final impression. These techniques have the advantage that the patient does not have to remain without the temporary crown for a longer period of time ${ }^{14}$.

\section{CONCLUSION}

Immediate implant placement is an ideal form of tooth replacement in a patient meeting the clinical criteria for this treatment modality. A careful placement technique and welldesigned temporary restorations can help achieve ideal aesthetics with implants in the anterior region of the mouth.

\section{DISCLOSURE}

None of the authors had any financial interest in the companies whose products have mentioned in this case report.

\section{REFERENCES}

1. Palacci P, Nowzari H. Soft tissue enhancement around dental implants. Periodontology 2000. 2008; 47(1): 11332.

2. Belser UC, Schmid B, Higginbottom F, Buser D. Outcome analysis of implant restorations located in the anterior maxilla: a review of the recent literature. Int $\mathrm{J}$ Oral Maxillofac Implants. 2004; 19(Suppl): 30-42.

3. Jivraj S, Chee W. Treatment planning of implants in the aesthetic zone. British dental journal. 2006; 201(2): 7789.

4. Azer SS. A Simplified Technique for Creating a Customized Gingival Emergence Profile for Implantâ€ Supported Crowns. Journal of Prosthodontics.19(6): 497-501.

5. Cho S, Shetty S, Froum S, Elian N, Tarnow D. Fixed and removable provisional options for patients undergoing implant treatment. COMPENDIUMNEWTOWN-. 2007; 28(11): 604.

6. Schwartz-Arad D, Chaushu G. Placement of implants into fresh extraction sites: 4 to 7 years retrospective evaluation of 95 immediate implants. Journal of periodontology. 1997; 68(11): 1110-6.

7. Greenstein G, Cavallaro J, Tarnow DP. Immediate dental implant placement: technique, part I. Dent Today.33(1): 98-100.

8. Palmer RM, Palmer PJ, Baker P. Immediate and early replacement implants and restorations. SADJ: journal of the South African Dental Association= tydskrif van die Suid-Afrikaanse Tandheelkundige Vereniging. 2008; 63(2): 074-9.

9. Schropp L, Isidor F. Timing of implant placement relative to tooth extraction. Journal of Oral Rehabilitation. 2008; 35(s1): 33-43.

10. Lazzara RJ. Immediate implant placement into extraction sites: surgical and restorative advantages. The International journal of periodontics \& restorative dentistry. 1989; 9(5): 332. 
11. Bichacho N, Landsberg CJ. A modified surgical/prosthetic approach for an optimal single implantsupported crown. Part II. The cervical contouring concept. Practical periodontics and aesthetic dentistry: PPAD. 1994; 6(4): 35-41; quiz

12. Alani A, Corson M. Soft tissue manipulation for single implant restorations. British dental journal.211(9): 4116.
13. den Hartog L, Raghoebar GM, Stellingsma K, Meijer HJA. Immediate loading and customized restoration of a single implant in the maxillary esthetic zone: a clinical report. The Journal of prosthetic dentistry. 2009; 102(4): 211-5.

14. Barzilay I. A Mo di fied Im p ression Technique for Ac curate Registration of Peri-implant Soft Tissues. J Can Dent Assoc. 2003; 69(2): 80-3. 